\title{
FERRITES AND DIFFERENT WINDING TYPES IN PERMANENT MAGNET SYNCHRONOUS MOTOR
}

\author{
Peter Sekerák * Valéria Hrabovcová* — Juha Pyrhönen ** \\ — Lukáš Kalamen * _ Pavol Rafajdus * _ Matúš Onufer *
}

\begin{abstract}
This paper deals with design of permanent magnet synchronous machines with ferrites. The ferrites became popular due to their low cost and cost increasing of $\mathrm{NdFeB}$. The progress in ferrite properties in the last decade allows the use of ferrites in high power applications. Three models of ferrite motors are presented. It is shown that also the type of stator winding and the shape of the slot opening have an important effect on the PMSM properties. The first motor has a distributed winding, the second motor has concentrated, non-overlapping winding and open stator slots. The third motor has a concentrated non-overlapping winding and semi - open slots. All models are designed for the same output power and they do not have the same dimensions. The paper shows how important the design of an electric machine is for excellent motor properties or better to say how the motor properties can be improved by an appropriate design.
\end{abstract}

K e y w o r d s: concentrated, non-overlapping winding, distributed winding, efficiency, permanent magnet synchronous motor (PMSM), ferrite

\section{INTRODUCTION}

The ferrite permanent magnets have been considered for a long time as the second grade material in comparison with rare earth magnets because they have got significantly lower remanence $B_{r}$, coercivity $H_{c}$ and energy product $\mathrm{BH}_{\max }$ than rare earth magnets. Nowadays the progress in ferrite properties and the high cost of $\mathrm{Nd}$ FeB gives more opportunities for their use. In Tab. 1 the main permanent magnet properties are shown as they have been gathered nowadays (2012) at web pages of their producers.

Table 1. PM material properties $[5,6]$

\begin{tabular}{lrcc} 
& $B H_{\max }$ & \multicolumn{1}{c}{$B_{r}$} & $H_{c}$ \\
\hline NdFeB & $200-500$ & $0.97-1.45$ & $740-1000$ \\
SmCo & $120-240$ & $0.85-1.10$ & $620-840$ \\
Ferrite & $7-42$ & $0.20-0.48$ & $120-360$ \\
AlNiCo & $10-35$ & $0.60-1.16$ & $40-120$ \\
\hline
\end{tabular}

AlNiCo magnets have higher remanence $\mathrm{Br}$ than ferrites but their low coercivity Hc can easily cause demagnetization of magnets. Ferrites, however have a wide linear demagnetization curve and therefore many authors have chosen ferrites for their research.

In [1] the authors have investigated two PMSMs; one with ferrite magnets and another with NdFeB magnets. Both of them have been of interior magnet type where the PMs have been totally embedded in the rotors. Authors have done complete analysis of parameters, losses and efficiencies of both motors. According to the results the rated efficiency of the ferrite motor has been about 1 $\%$ lower than the efficiency in the motor with $\mathrm{NdFeB}$. The volume of ferrites has been five times as high as the volume of $\mathrm{NdFeB}$.
In [2] the authors have presented two PMSMs, one with SmCo magnets and another, again, with ferrites. The efficiency of the ferrite motor was about $0.5 \%$ lower at the same output power. The weight of ferrites is 2.5fold in comparison with the weight of SmCo.

In [3] the authors have presented a PMSM with new rotor design and with ferrites and damper winding. Authors compare their machine with another one at constant ferrite PM volume. The new designed PMSM has 4 $\%$ improvement in efficiency.

In [4] the authors investigate losses in permanent magnet motors with concentrated non-overlapping windings and compare them with losses in a PMSM with distributed winding. All motors have the same dimensions, air gap length and the same amount of permanent magnet material. Authors have presented five models of PMSM with different slots per pole per phase $q$. The highest efficiency has been achieved with a configuration with 24 stator slots and 20 rotor poles.

In [9] the authors have investigated PMSM with NdFeB and then the PM was replaced by ferrites: a) with the same volume, b) with an increased volume to get the same output power. It was shown that comparable properties have been achieved if greater motor size can be accepted. Therefore, the greater care has been devoted to the ferrite motors, looking for more appropriate design, mainly on the stator.

In this paper the influence of the stator winding on PMSM properties is investigated. For this purpose three PMSM models are created. The first one is constructed with a distributed winding. The second and the third model have concentrated non-overlapping windings. The difference between them is the stator slot shape: The first

\footnotetext{
${ }^{*}$ University of Žilina, Faculty of Electrical Engineering, Univerzitná 1, 01026 Žilina, Slovakia, valeria.hrabovcova.@uniza.sk ** Lappeenranta University of Technology, Lappeenrante, Finland
} 
one is of open slot type and the second one is of semi closed slot type

\section{PMSM DESIGN}

The goal of the PMSM design process should be a motor which can develop required output power with excellent efficiency and at low cost. At first the choice between $\mathrm{NdFeB}$ and ferrites has been done in favour of ferrites. According to [6] the cost per $\mathrm{kg}$ of $\mathrm{NdFeB}$ is at present about 30 times the cost of ferrite.

For the PMSM design ferrite with the following parameters in operating temperature of $75^{\circ} \mathrm{C}$ was selected: $B_{r}$ $=0.45 \mathrm{~T}, H_{c}=340 \mathrm{kA} / \mathrm{m}$ and $B H_{\max }=40 \mathrm{kJm} / \mathrm{m}^{3}$. The all PMSMs have rotor surface magnets. The other parameters and design process will be described below.

\subsection{Initial data of PMSM}

The initial data of PMSM given in Tab. 2 have been chosen on a base of an existing PMSM with NdFeB. In the tables this machine is designated as "original".

Table 2. Initial data of PMSM

\begin{tabular}{lll}
\hline Data & Symbol & Value \\
\hline Shaft power (W) & $P_{\text {out }}$ & 2000 \\
Speed (rpm) & $n$ & 360 \\
Torque (Nm) & $T$ & 53 \\
Phase voltage (V) & $U_{\text {sph }}$ & 230 \\
Phase number (-) & $m$ & 3 \\
Pole pairs (-) & $p$ & 6 \\
Frequency (Hz) & $f_{s}$ & 36 \\
Air-gap length (mm) & $\delta$ & $1+1$ \\
Power factor (-) & $\cos \phi$ & 0.9 \\
Desired efficiency (-) & $\eta$ & 0.9 \\
Coercivity of PM (A/m) & $H_{c}$ & 340000 \\
Remanence of PM (T) & $B_{r}$ & 0.45 \\
Permeability of PM (-) & $\mu_{r}$ & 1.054 \\
Relative magnett width $(-)$ & $\alpha_{P M}$ & 0.8 \\
Stator-core space factor $(-)$ & $k_{f e}$ & 0.95 \\
Permitted $B$ in tooth $(\mathrm{T})$ & $B_{d p e r}$ & 1.5 \\
Permitted $B$ in yoke(T) & $B_{\text {yper }}$ & 1 \\
\hline
\end{tabular}

Table 2 shows all necessary data for the PMSM design. The magnetic air gap $\delta$ is $2 \mathrm{~mm}$ allowing $1 \mathrm{~mm}$ for a magnet retaining ring.

Next the material of the magnetic circuit M800-65 was chosen. The specific loss of this material at $1 \mathrm{~T}$ and $50 \mathrm{~Hz}$ is $p_{10}=3.1 \mathrm{Wk} / \mathrm{g}$. Indirect air cooling has been chosen. The PMSM configuration will be described in chapter 2.3.

\subsection{Rotor dimensions}

It is obvious that rotor surface mounted ferrites cannot provide so high level of magnetic flux density $B_{\delta \max 1}$ as it is recommended in technical literature, being between 0.8 and $1.05 \mathrm{~T}$. The targeted maximal value of $B_{\delta \max 1}$ in ferrite motor was $0.45 \mathrm{~T}$, see FEM analysis, Fig. 8d.
For $P_{\text {out }}=2000 \mathrm{~W}$ the linear current density $A=30$ $\mathrm{kA} / \mathrm{m}$ was selected.

The rotor volume $V_{r}$ for rated torque can be estimated by torque and average tangential stress $\sigma_{F t a n}[7]$

$$
V_{\mathrm{r}}=\frac{T}{2 \sigma_{F \tan }}, \quad \sigma_{F \tan } \approx \frac{A B_{\delta \max 1} \cos \phi}{\sqrt{2}}
$$

where power factor is chosen from Tab. 2 .

For the $A$ and $B_{\delta}$ values chosen the tangential stress is $\sigma_{\text {Ftan }}=7636 \mathrm{~Pa}$ and the required volume of rotor is $V_{r}=3.47 \times 10^{-3} \mathrm{~m}^{3}$. For this volume the rotor diameter $D_{r}=0.19 \mathrm{~m}$ and equivalent core length $l=0.12 \mathrm{~m}$ have been calculated. There are no cooling channels and therefore the core length of the machine is by, [11]

$$
l=l^{\prime}-2 \delta \text {. }
$$

\subsection{Stator and PM dimensions}

The chosen $B_{\delta \max 1}$ represents the amplitude of the fundamental harmonic component of the air gap magnetic flux density. Due to the rectangular shape of PM, the waveform of the magnetic flux density in the air gap is approximately rectangular. The maximum value of this waveform is calculated by

$$
B_{\max }=\frac{\pi B_{\delta \max 1}}{4 \sin \left(\frac{\alpha_{P M} \pi}{2}\right)}
$$

This value is used for computation of the tooth width $b_{d}$ (Fig. 6) not to exceed the maximal magnetic flux density in the stator tooth $B_{d p e r}$, see Tab. 2

$$
b_{d}=\frac{l^{\prime} \tau_{u}}{k_{F e} l} \frac{B_{\max }}{B_{d p e r}}, \quad \tau_{u}=\frac{\pi D_{s}}{Q}
$$

where $\tau_{u}$ is the slot pitch, with the stator bore diameter $D_{s}=D_{r}+2 \delta$. For the stator dimension it is necessary to calculate the slot dimensions. The first step is to calculate the stator turns needed for the induced EMF by PM in the first step equal to $U_{s p h}$

$$
N_{s}=\frac{U_{s p h}}{\sqrt{2} \pi f k_{1 s} \Phi_{a v}} .
$$

where $k_{w s}$ is the operating harmonic winding factor, see chapter $3, \Phi_{a v}$ is the amount of magnetic flux per pole and can be calculated by

$$
\Phi_{a v}=\frac{2}{\pi} B_{\delta \max 1} \frac{D_{s} \pi}{2 p} l^{\prime} .
$$

When the number of stator turns is known the number of conductors in one slot can be determined

$$
z_{Q}=N_{s} / p q,
$$

here $z_{Q}$ has to be integral number and due to it can be rounded. Next procedure is focused on calculation of cross section area of all conductors. The RMS stator current $I_{s}$ has to be estimated by

$$
I_{s}=\frac{P}{m \eta U_{s p h} \cos \phi}
$$




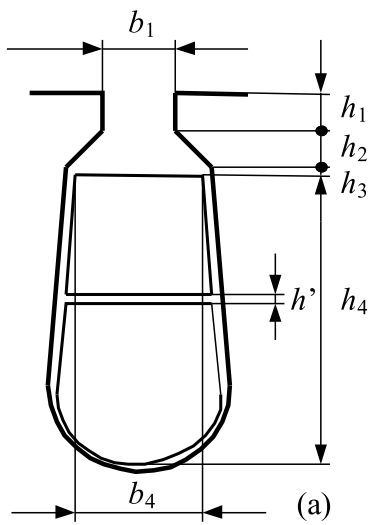

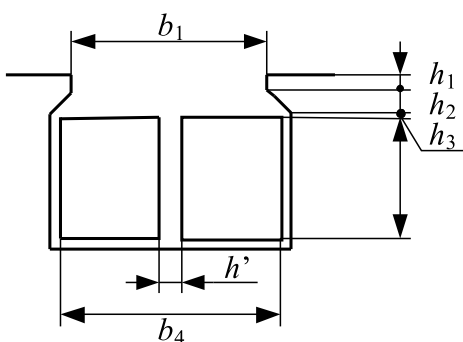

(b)

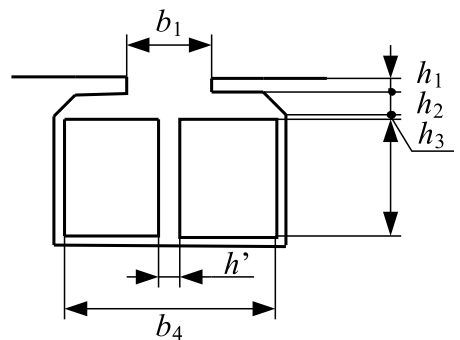

(c)

Fig. 1. The stator slots: (a) - distributed winding, (b) - concentrated non-overlapping winding, open slot type, (c) - concentrated non-overlapping winding, semi-closed slot type

The stator current density has been selected to $J_{s}=2.5$ $\mathrm{A} / \mathrm{mm}^{2}$. The cross sectional area of the stator slot can be determined

$$
S_{C S}=\frac{I_{s}}{J_{s}} \frac{z_{Q}}{k_{C S}}
$$

where $k_{C S}$ is the winding space factor which takes into account the insulation. The calculated stator parameters to both kinds of winding are shown in Tab. 3 .

Table 3. Stator parameters

\begin{tabular}{cccc}
\hline Winding & $\begin{array}{c}\text { Distri- } \\
\text { buted }\end{array}$ & $\begin{array}{c}\text { Concen- } \\
\text { trated }\end{array}$ & $\begin{array}{c}\text { Original } \\
\text { PMSM }\end{array}$ \\
\hline$B_{\max }(\mathrm{T})$ & & 0.37 & 0.5080 \\
\hline$\tau_{u}(\mathrm{~m})$ & 0.0127 & 0.0338 & 0.0097 \\
$b_{d}(\mathrm{~mm})$ & 3.4 & 9.15 & 4.3 \\
$N_{s}(-)$ & 840 & 912 & 420 \\
$z_{Q}(-)$ & 112 & 0.0338 & 56 \\
\hline$I_{s}(\mathrm{~A})$ & & 304 & $4.9^{*}$ \\
\hline$S_{C S}\left(\mathrm{~mm}^{2}\right)$ & 233 & 636 & 141 \\
\hline
\end{tabular}

* value obtained at rated load and optimal stator phase voltage $U_{s p h}=180 \mathrm{~V}$

When the parameter $S_{C S}$ is known it is possible to calculate stator slot dimensions. The cross sectional areas of slots are shown in Fig. 1 (a) - for distributed winding, (b) - for concentrated non-overlapping winding with open slot type, and (c) - concentrated non-overlapping winding with semi-closed slot type.

For a better understanding the motor with distributed winding is called motor A, motor with concentrated nonoverlapping winding and open slot type is motor B and motor with concentrated non-overlapping winding and semi-closed slot type is motor C.

All dimensions in Fig. 1 are given in Tab. 4. The Carters factor has been calculated on the base of the slot dimensions.
Table 4. Slot dimensions and Carter's factor

\begin{tabular}{cccc}
\hline Motor & A-type & B-type & C-type \\
\hline$b_{1}(\mathrm{~mm})$ & 3 & 21.16 & 6.85 \\
$b_{4}(\mathrm{~mm})$ & 9.76 & 25.83 & 25.83 \\
$h_{1}(\mathrm{~mm})$ & 1 & 1 & 1 \\
$h_{2}(\mathrm{~mm})$ & 2.1 & 2.1 & 2.1 \\
$h_{3}(\mathrm{~mm})$ & 1 & 1 & 1 \\
$h_{4}(\mathrm{~mm})$ & 22.54 & 20.54 & 20.54 \\
$h^{\prime}(\mathrm{mm})$ & 0.5 & 0.5 & 0.5 \\
$k_{C}(-)$ & 1.007 & 1.99 & 1.09 \\
\hline
\end{tabular}

As it is seen motor B has the largest Carter's coefficient $k_{C}$, what is caused by the big slot opening. This is used to calculate equivalent air gap

$$
\delta_{e}=k_{C} \delta
$$

The magnetic voltage of the air gap is given by

$$
U_{m \delta \delta}=\frac{B_{\max }}{\mu_{0}} \delta_{e}
$$

where $\mu_{0}$ is the permeability of vacuum.

The total magnetic voltage $U_{m t o t}$ is equal to the current linkage $H_{c} h_{P M}$

$$
\begin{gathered}
U_{m t o t}=U_{m \delta \delta}+U_{m P M}+U_{m d s}+ \\
+\frac{U_{m y s}}{2}+\frac{U_{m y r}}{2}=H_{c} h_{P M}
\end{gathered}
$$

where $U_{m d s}, U_{m y s}$ and $U_{m y r}$ are the magnetic voltages of stator tooth, stator yoke and rotor yoke, respectively. The magnetic voltage over the permanent magnet is

$$
U_{m P M}=\frac{H_{c}}{B_{r}} B_{\max } h_{P M}
$$

In practice the magnetic voltages in iron parts of electric machine are small in comparison with magnetic voltages over air gap or, especially, the permanent magnet. Therefore, the magnetic voltages $U_{m d s}, U_{m y s}$ and $U_{m y r}$ can be ignored in rotor surface PM machine without making a big mistake. By substituting (15) into (14) the permanent magnet height can be calculated

$$
h_{P M}=\frac{U_{m \delta \delta}}{H_{c}-\frac{H_{c}}{B_{r}} B_{\max }}
$$


The last important dimension for a PMSM design is the height of the stator yoke $h_{y s}$. Its value can be gained on the base of the magnetic flux and cross sectional area of it

$$
h_{y s}=\frac{\Phi_{a v}}{2 k_{F e} l B_{y p e r}}
$$

where $k_{F e}$ and $B_{\text {yper }}$ are taken from Tab. 2. Table 5 shows the results of the calculated parameters $h_{P M}$, $w_{P M}$ and hys. These parameters are shown in Fig. 6.

Table 5. Calculated parameters $h_{P M}, w_{P M}, l_{P M}$ and $h_{y s}$

\begin{tabular}{ccccc}
\hline Motor & A-type & B-type & C-type & Original \\
\hline$h_{P M}(\mathrm{~mm})$ & 15 & 21 & 21 & 4 \\
$w_{P M}(\mathrm{~mm})$ & 36.6 & 35.5 & 35.4 & 32 \\
$l_{P M}(\mathrm{~mm})$ & 40 & 40 & 40 & 35 \\
$h_{y s}(\mathrm{~mm})$ & 10 & 10 & 10 & 14.1 \\
\hline
\end{tabular}

\section{STATOR WINDING}

It is possible to design a PMSM with a distributed winding and also with a concentrated non-overlapping winding. Both winding types are popular in PMSMs and in the next chapters the design process is shown. Schematically both types are shown in Fig. 2 .

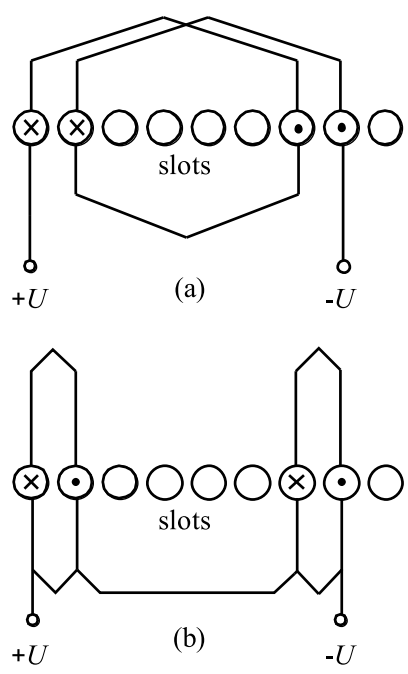

Fig. 2. Basic scheme of: (a) - distributed winding, (b) - concentrated winding

The concentrated non-overlapping winding becomes popular due to its advantages because of very good manufacturability which decreases cost, shorter nonoverlapping end turns or higher power density. The next chapter 3.1 shows that the design procedure of both windings is similar.

\subsection{Distributed winding}

Stator winding is designed as a double layer type. The stator slot number $Q$ has to be chosen to next calculation.
In the theory of the winding design the concept of "base winding" is used. Base winding is a part of the stator winding which can be repeated periodically. It is possible to build stator winding by these base windings due to their symmetry. The parameters of a base winding are marked by superscript * For the PMSM with distributed winding $Q=45$. This number has been chosen on the base of the slot number in the original PMSM with $\mathrm{NdFeB}$ magnets. The winding with the chosen stator slots and pole pairs will be fractional. The number of slots per phase per pole $q$ is

$$
q=\frac{Q}{2 p m}=\frac{z}{n}
$$

The next stator winding design depends on the denominator $n$ and the type of winding. It is possible to make one layer or two layer winding. For our configuration with 45 slots, 6 pole pairs and 3 phases is $q=5 / 4$. In this case of even denominator $n$ the procedure is as follows:

The largest common divider $t$ of slot number $Q$ and $p$ and further the number of slots of base windings $Q *$ and the pole pairs of the base winding $p *$ are

$$
t=\frac{2 p}{n}, \quad Q *=\frac{Q}{t}, \quad p *=n / 2
$$

The number of layers of the phasor diagram $t *=1$ for a double layer winding, and even number $n$. Thus number of $Q$ and the angle between two phasors $\alpha_{d}$ and the angle between two slots $\alpha_{p}$ is determined by

$$
Q^{\prime}=\frac{Q *}{t *}, \quad \alpha_{d}=360 \frac{t *}{Q *}, \quad \alpha_{p}=360 \frac{p *}{Q *}
$$

Every phase has $Q / m$ phasors. Every phase has two components, one positive and one negative, eg $U$ and $-U$. If the number $Q / m$ is odd the positive and negative component are not equal. For example if $Q / m$ is 5 , as in our case, the system of winding distribution will be used:

$$
\begin{array}{cccccc}
U & -W & V & -U & W & -V \\
3 & 2 & 3 & 2 & 3 & 2
\end{array}
$$

The distributed winding is assembled of three base windings shown in Fig. 3.

\subsection{Concentrated winding}

Stator winding is double layer type. For PMSM the stator slots has been chosen $Q=18$. For a configuration of 18 slots, 6 pole pairs and 3 phases, the number of slots per pole per phase is $q=1 / 2$. Seeing that $n$ in a concentrated nonoverlapping winding is even as in the distributed winding, the design process is the same.

\subsection{Windings layout}

The phasor diagram is necessary for the construction of the base windings. Table 6 shows all calculated parameters mentioned above.

The phasor diagrams of the base windings constructed by Tab. 6 are shown in Fig. 3a and 4a. The arrangements of both base windings are shown in Fig. $3 \mathrm{~b}$ and 

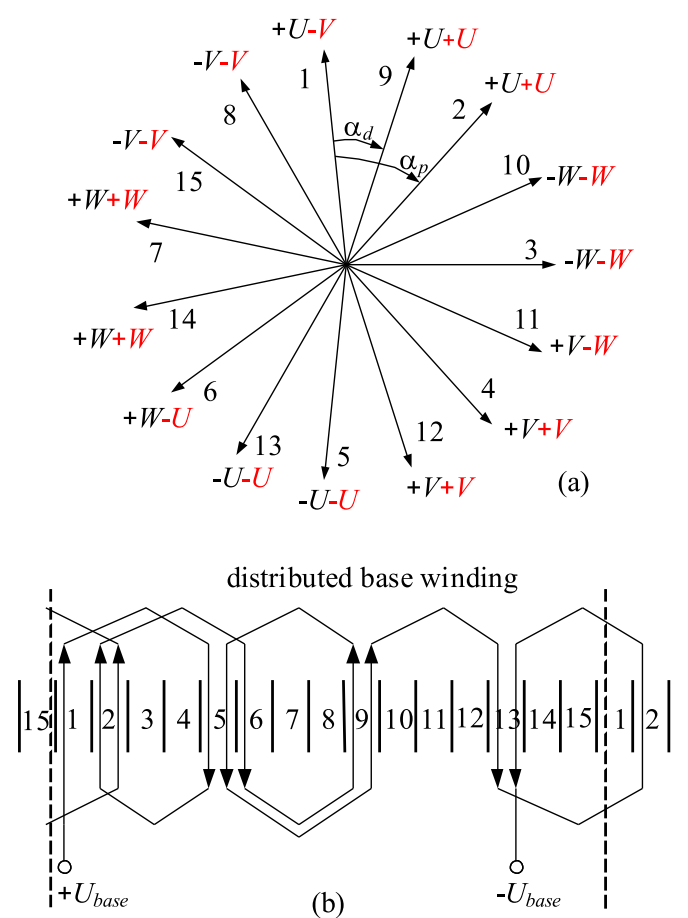

Fig. 3. Distributed base winding: (a) - phasor diagram, (b) winding arrangement in the slots

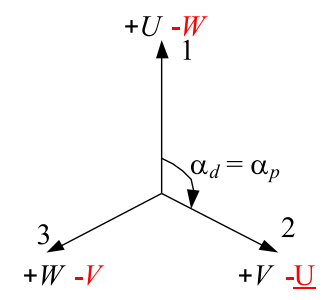

(a)

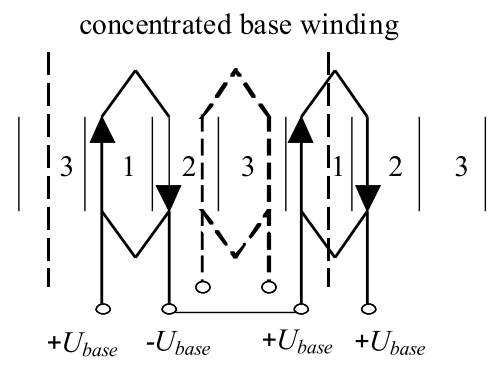

(b)
Fig. 4. (a) - Phasor diagram of the concentrated non-overlapping base winding, (b) - winding arrangement in the slots, full line represents two base windings of phase $U$, dashed line represents one base winding of phase $V$.

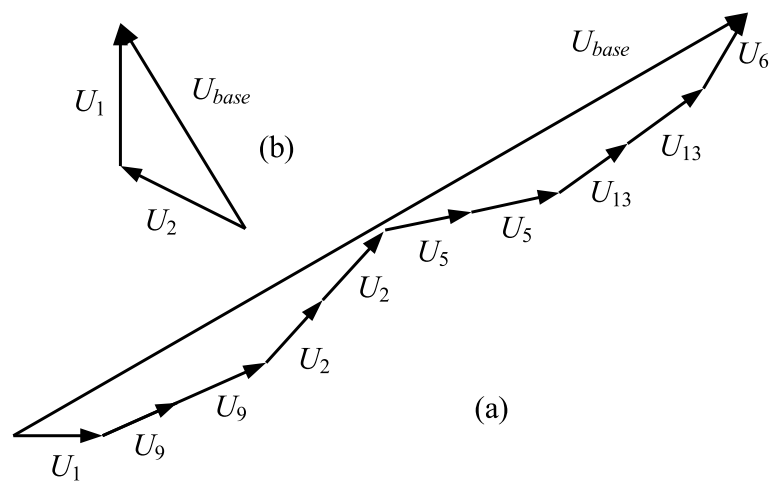

Fig. 5. The phasors of the phase $U$ for the calculation of winding factor: (a) - distributed, (b) - concentrated winding

4b. The total distributed winding is completed by three base windings, shown in Fig.3b. The complete concentrated non-overlapping winding is assembled of six base windings shown in Fig. $4 \mathrm{~b}$.

Table 6. Stator winding parameters

\begin{tabular}{ccc}
\hline $\begin{array}{c}\text { Winding } \\
\text { Type: }\end{array}$ & $\begin{array}{c}\text { Distributed } \\
\text { double-layer }\end{array}$ & $\begin{array}{c}\text { Concentrated } \\
\text { double-layer }\end{array}$ \\
\hline$q$ & $5 / 4$ & $1 / 2$ \\
$t$ & 3 & 6 \\
$Q_{*}$ & 15 & 3 \\
$p *$ & 2 & 1 \\
$t *$ & 1 & 1 \\
$Q^{\prime}$ & 15 & 3 \\
$\alpha_{d}$ & $24 \mathrm{deg}$ & $120 \mathrm{deg}$ \\
$\alpha_{p}$ & $48 \mathrm{deg}$ & $120 \mathrm{deg}$ \\
$Q^{\prime} / m$ & 5 & 1 \\
\hline
\end{tabular}

The winding factors of both windings for the fundamental harmonic are determined by means of graphics method shown in Fig 5.

\section{CROSS SECTION AREA OF THE DESIGNED PMSM}

Fig. 6 shows cross section areas of one quarter of all three motors. Table 6 shows the final dimensions of all three PMSMs and also the original PMSM.

Table 7. Final dimensions and volumes of designed PMSM

\begin{tabular}{ccccc}
\hline Motor & A-type & B-type & C-type & Original \\
\hline$D_{\text {rve }}(\mathrm{m})$ & 0.16 & 0.148 & 0.148 & 0.147 \\
$D_{\text {se }}(\mathrm{m})$ & 0.267 & 0.261 & 0.261 & 0.22 \\
PM volume $\left(\mathrm{cm}^{3}\right)$ & 794 & 1071 & 1071 & 215 \\
Iron volume $\left(\mathrm{m}^{3}\right)$ & 0.0042 & 0.0035 & 0.00354 & 0.0041 \\
\hline
\end{tabular}

\section{SIMULATION OF THE PMSM OPERATION}

In this chapter the operation of designed motors is investigated by simulations. The main interest is focused on $\mathrm{V}$ - curves, maximal developed torque and ripple torque, losses and efficiency. For this investigation some parameters of PMSM have to be known, see Tab. 8. The parameters have been determined by procedures applied in [8]. The parameters of original motor have been verified by measurements [8] and [9], therefore we suppose that parameters and properties of new designed motors are also reliable. Parameters from Tab. 8 have been put into the equivalent circuit model, see Fig. 7.

\subsection{Air-gap magnetic flux density}

The air gap magnetic flux density B in all three motors has been investigated by means of 2D FEM models. Fig. 8 shows the waveforms of $\mathrm{B}$ and their harmonic components at no-load. 
(a)

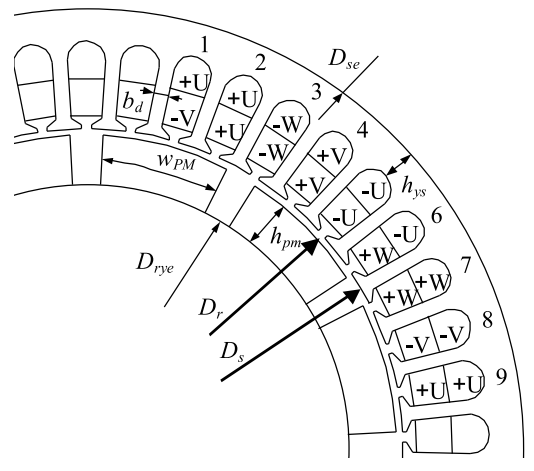

(b)

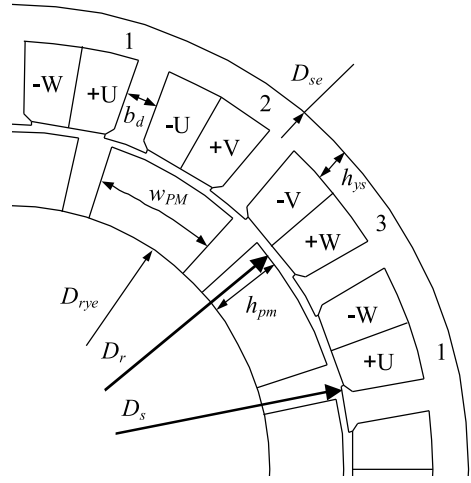

(c)

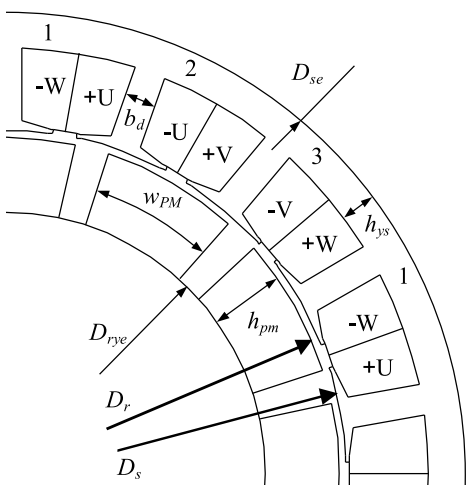

Fig. 6. The cross sectional areas of PMSMs with different winding arrangements: (a) - motor A, (b) - motor B, (c) - motor C
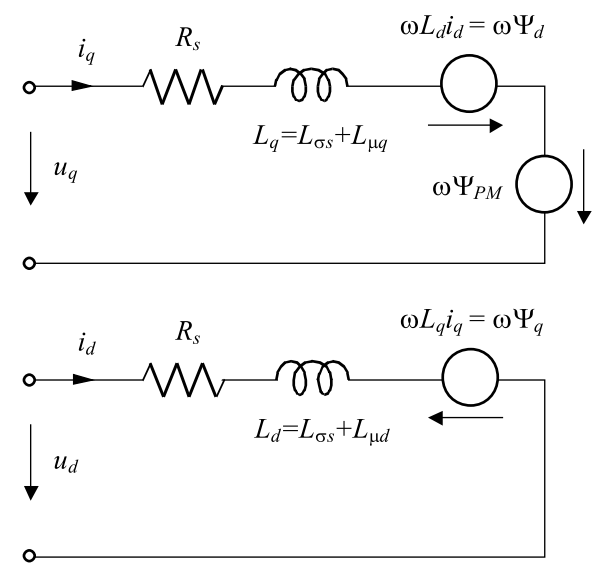

Fig. 7. The equivalent circuit of PMSM in dq frame

Table 8. PMSM equivalent circuit parameters

\begin{tabular}{ccccc}
\hline Motor & A-type & B-type & C-type & Original \\
\hline$R_{s} *(\Omega)$ & 6.05 & 4.77 & 4.77 & 3.92 \\
$L_{\sigma s}(\mathrm{H})$ & 0.0933 & 0.0935 & 0.1489 & 0.0289 \\
$L_{\mu d}(\mathrm{H})$ & 0.0297 & 0.0204 & 0.0219 & 0.024 \\
$L_{\mu q}(\mathrm{H})$ & 0.0297 & 0.0204 & 0.0219 & 0.076 \\
$\Psi_{P M}(\mathrm{~Wb})$ & 1.352 & 1.179 & 1.34 & 0.828 \\
$E_{P M}(\mathrm{~V})$ & 211 & 188 & 213 & 132.5 \\
\hline
\end{tabular}

* stator resistance at $20{ }^{\circ} \mathrm{C}$

The fundamental components of $B_{\delta}$ are about $0.4 \mathrm{~T}$, which is very low in comparison with PMSM with $\mathrm{NdFeB}$ magnets. $\mathrm{NdFeB}$ magnets can provide magnitudes of $B_{\delta}$ up to $1 \mathrm{~T}$. Low $B_{5}$ provided by ferrites has to be taken into account in a PMSM design and a higher number of stator turns is required, see Tab. 3. As a result the proportions of iron and copper in the teeth are changed.

\subsection{Torque investigation}

The ability to develop torque is a very important attribute in a PMSM. Fig. 9 shows the maximal values of developed torque of all three motors.

All three machines are able to develop the rated torque $T_{N}=53 \mathrm{Nm}$. The highest torque can be developed by motor B with $T_{\max }=90 \mathrm{Nm}$. On the contrary the maximal torque of motor $\mathrm{C}$ has been lowest $T_{\max }=68 \mathrm{Nm}$. The next parameter investigated is the ripple torque, see Fig. 10. All three machines are loaded by the rated torque $T_{N}=53 \mathrm{Nm}$.

It is seen that motor A has the lowest torque ripple and its peak to peak value is $T_{\text {ripp }}=4 \mathrm{Nm}$. Motor B has $T_{\text {ripp }}=5.2 \mathrm{Nm}$. The highest value $T_{\text {ripp }}$ has been found in motor $\mathrm{C}, T_{\text {ripp }}=8.5 \mathrm{Nm}$.

In synchronous machines with classical excitation by means of field current the $\mathrm{V}$ - curves present stator current $I_{s}$ versus field current If. In PMSM these $\mathrm{V}$ - curves are not possible due to constant excitation by PM. The V-curves in this case can be plotted as stator current Is versus ratio of Usph/EPM at different loads. All three motors have been loaded from $1 \mathrm{~kW}$ to $2.5 \mathrm{~kW}$. The stator terminal phase voltage has been changed in the range from $242 \mathrm{~V}$ to $173 \mathrm{~V}$. The simulated waveforms are shown in Fig. 11.

\section{$5.3 V$ - curves}

The V-curves can show the optimal operating point for different loads and voltage levels. The optimal point means the lowest Joule losses that represent the majority in all losses. From Fig. 11 it is seen that the investigated motors work very close to this optimal point. The current Is at this point has been chosen as nominal.

\subsection{Losses}

Losses have been investigated in all three motors. Next types of losses have been taken in to account:

- Joule losses $\Delta P_{J}$

- Iron losses $\Delta P_{\text {iron }}$

- Mechanical losses $\Delta P_{\text {mech }}$

The losses in the PM have been calculated according to [10] and due their low values they have been neglected. The main reason is the high resistivity of ferrites and therefore the eddy currents and eddy current losses are negligible in ferrites PM. The resistivity of ferrites $\rho_{\text {ferr }}=10^{6} \Omega \mathrm{cm}$ is very high in comparison with the resistivity of $\mathrm{NdFeB} \rho_{N d F e B}=2 \times 10^{-4} \Omega \mathrm{cm}$. 

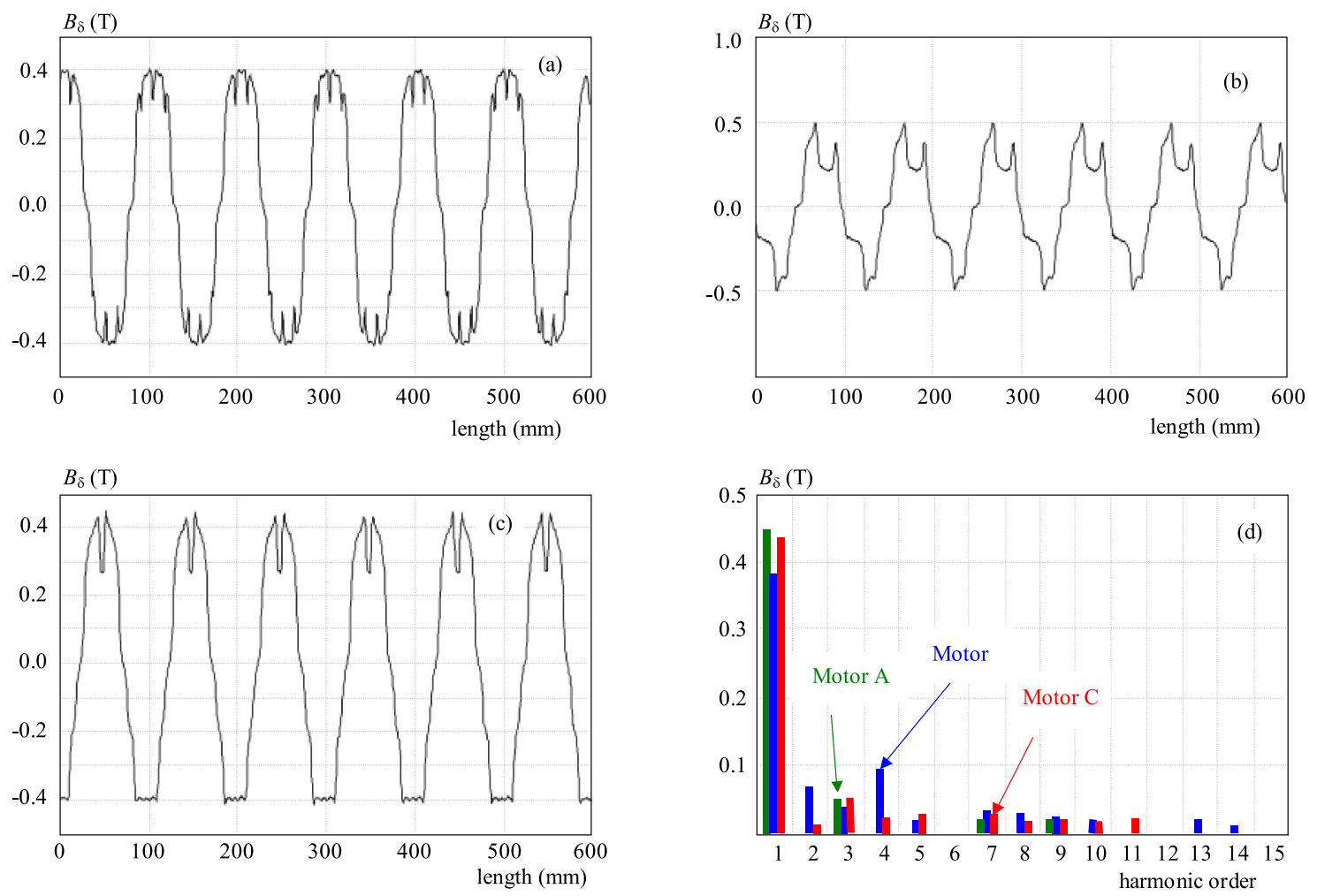

Fig. 8. The waveforms of B in: (a) - motor A, (b) - motor B, (c) - motor C, and (d) - their harmonic components

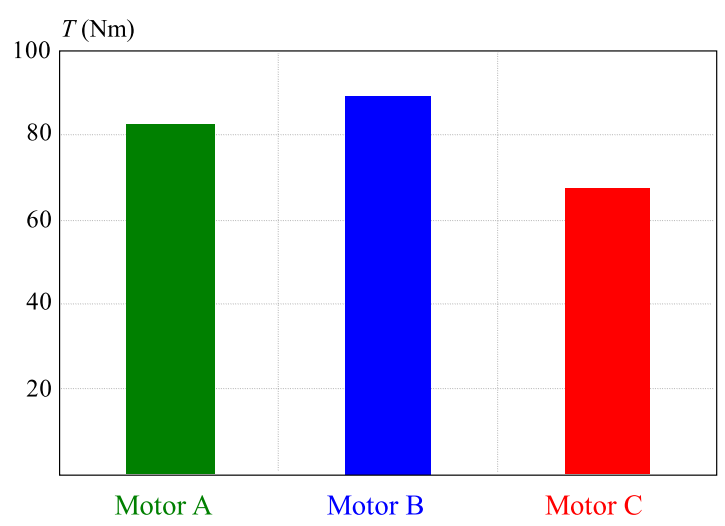

The Joule losses are calculated by

$$
\Delta P_{J}=3 R_{s p h} I_{s}^{2}
$$

where $R_{s p h}$ is the phase resistance at $75^{\circ} \mathrm{C}$. Iron losses in $n$-th element (element means tooth, yoke, etc.) have been calculated by following formula [7]

$$
\Delta P_{\text {iron }, n}=p_{10}\left(\frac{B_{\max , n}}{1 T}\right)^{2} m_{i r o n, n}\left(\frac{f}{50}\right)^{1.3}
$$

Fig. 9. The maximal developed torque of all three motors at rotor speed $n=360 \mathrm{rpm}$
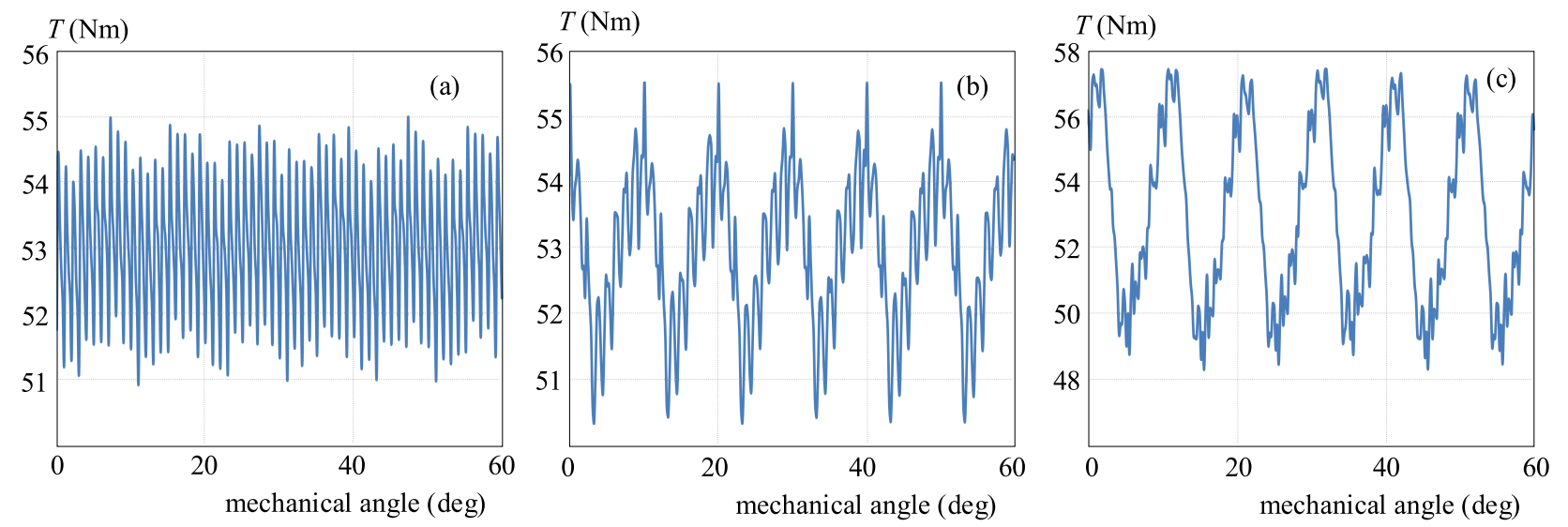

Fig. 10. The ripple torques of investigated machines: (a) - motor A, (b) - motor B, (c) - motor C 

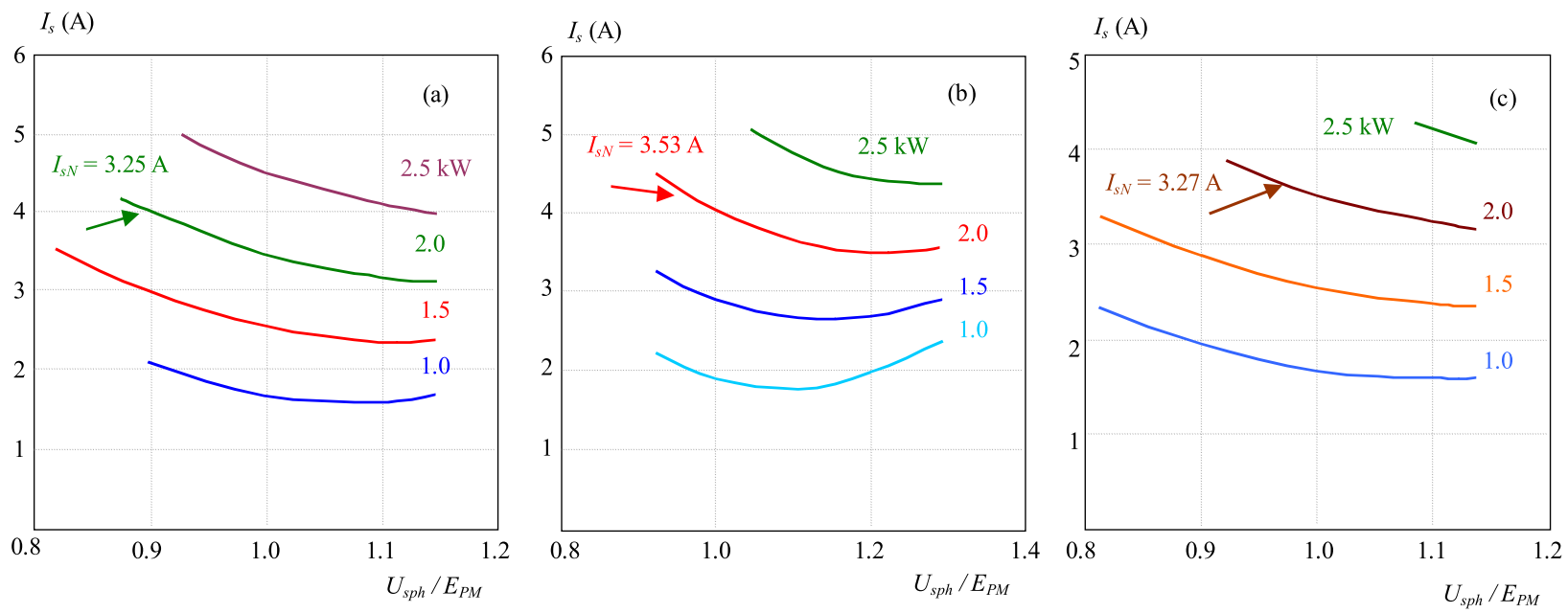

Fig. 11. The $V$ - curves of the investigated machines: (a)- motor $\mathrm{A}, E_{P M}=211 \mathrm{~V}$, (b) - motor B, $E_{P M}=188 \mathrm{~V}$, (c) - motor C, $E_{P M}=213 \mathrm{~V}$

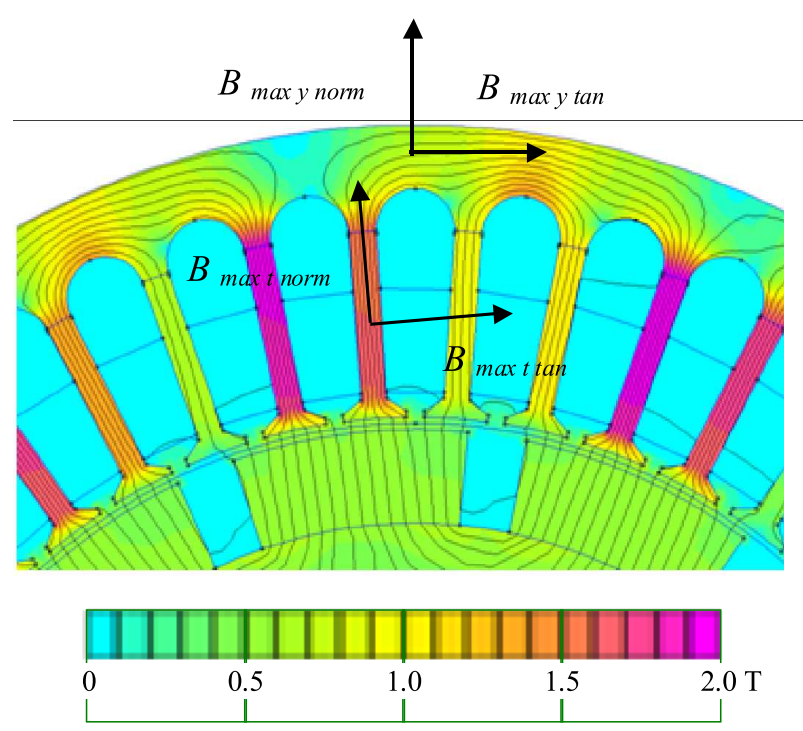

Fig. 12. The cross section of the $2 \mathrm{D}$ FEM model with magnetic flux densities description at rated voltage and rated load

where $p_{10}=3.1 \mathrm{~W} / \mathrm{kg}$ is iron loss per unit of mass at magnetic flux density $B=1 \mathrm{~T}, B_{\max , n}$ is the amplitude of the magnetic flux density in the $n$-th element of machine and $m_{\text {iron,n }}$ is mass of $n$-th element of machine. The investigation was done by means of FEM. The amplitude of the magnetic flux density $B_{\max , n}$ in the $n$-th element is given by the tangential and normal component

$$
B_{\max , \mathrm{n}}=\sqrt{B_{\max , \mathrm{n}, \tan }^{2}+B_{\max , \mathrm{n}, \mathrm{norm}}^{2}}
$$

that have been taken from 2D FEM model, see Fig. 12.

Figure 13 shows the waveforms of the magnetic flux densities gained from points marked in Fig. 12 .

The mechanical loss has been taken into account and its value is $P_{\text {mech }}=40 \mathrm{~W}$ for all three motors. This value has been calculated on the base an analytical approach in [7].
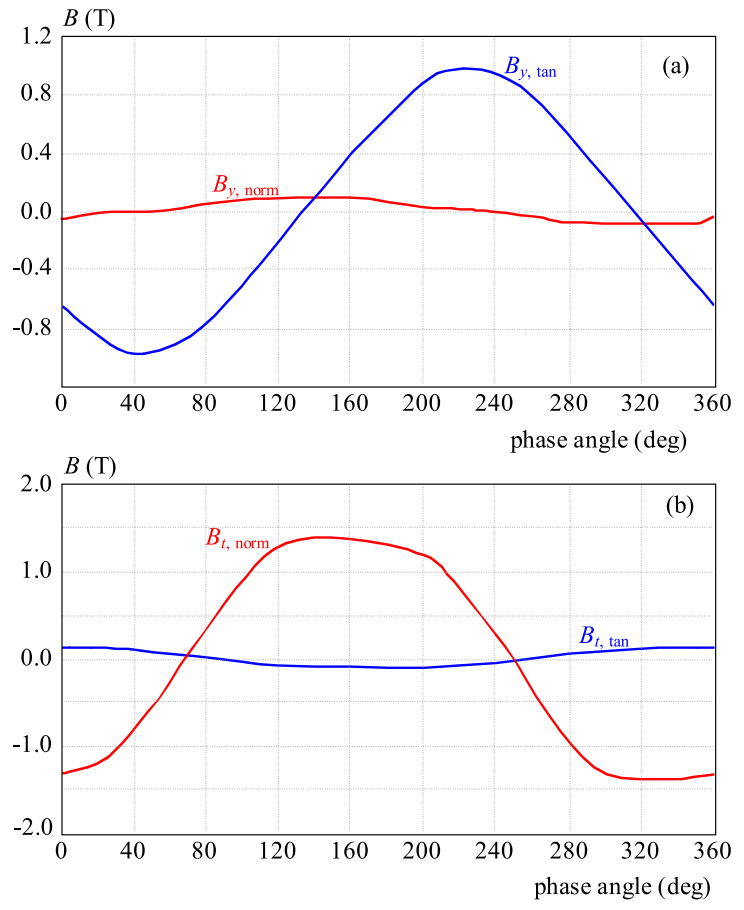

Fig. 13. The magnetic flux densities of motor $A$ at the rated voltage and rated load in: (a) - stator yoke, (b) - stator tooth

Figure 14 shows the loss comparison of all three motors at rated voltage and load.

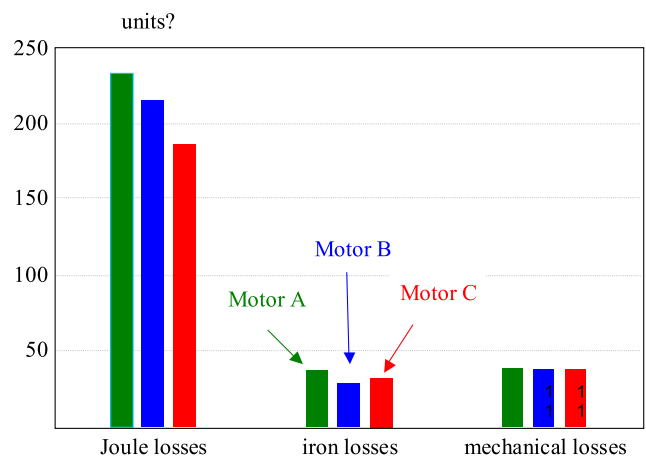

Fig. 14. Comparison of losses 
On the base of data in Fig. 14 the efficiencies for the motors have been calculated and are shown in Tab. 9.

Table 9. Calculated efficiency of proposed PMSMs

\begin{tabular}{ccccc} 
Motor & A-type & B-type & C-type & Original \\
\hline Efficiency (\%) & 86.5 & 87.5 & 88.4 & 86.5
\end{tabular}

\section{CONCLUSION}

The paper shows how the motor properties can be improved by an appropriate design. A design process of different PMSMs has been presented in the paper. Three motors with ferrites have been designed, one with distributed winding and two with concentrated winding and in the end compared with a NdFeB SMPM. It is seen that ferrites can be useful in PMSM design also when premium efficiency is required and machine properties with ferrites can be comparable with NdFeB-machines. A high number of stator turns is required in a PMSM with ferrites. That fact can cause a rapid increase of stator leakage and magnetizing inductance which leads to lower torque capability. The calculations and simulations have shown that semi closed slot type increases the stator leakage inductance and therefore in PMSMs with concentrated nonoverlapping windings the open slot type should be used. Although the PMSM with ferrites requires big volume of ferrite PM, the cost of ferrites is low in comparison with $\mathrm{NdFeB}$. By using of a concentrated non-overlapping winding the iron parts' volume has been decreased in comparison with the original PMSM with NdFeB.

\section{REFERENCES}

[1] LIANGFANG-LEE, B. H.-LEE, J. J.-KIM, H. J.-JUNGPYOHONG : Study on high-efficiency characteristics of interior permanent magnet synchronous motor with different magnet material, Electrical Machines and Systems (2009), ICEMS 2009.

[2] RICHTER, E.-NEUMANN, T.: Line start permanent magnet motors with different material, IEEE Trans. Magnetics 20, 1762-1764.

[3] CHAudhari, B. N.-FERnAndes, B. G. : Synchronous motor using ferrite magnets for general purpose energy efficient drive, TENCON 99, 1999,.

[4] JUSSila, H.-SALMineN, P.-PYRHONEN, J. : Losses of a Permanent Magnet Synchronous Motor with Concentrated Windings, PEMD, 2006, ISBN: 0-86341-609-8.

[5] www.hitachi-metals.co.jp/e/prod/prod03/p03_10.html.

[6] www.magsy.cz.

[7] PYRHONEN, J., JOKINEN, T., HRABOVCOVA, V.: Design of rotating electrical machines, Wiley, 2008, ISBN: 978-0-470 $-69516-6$.
[8] SEKERÁK, P.-HRABOVCOVÁ, V.-PRAFAJDUS, P.KALAMEN, L. : Interior Permanent Magnet Synchronous Motor Parameters Identification, ISEM 2010, Prague, 2010, 09, 8.-9. AFC, pp. 107-116, 978-80-01-04621-0.

[9] SEKERÁK, P.—HRABOVCOVÁ-V., KALAMEN-L., RAFAJDUS, P.-ONUFER, M.: Synchronous Motors with Different PM Materials, in Proc. of ELEKTRO 2012, 24-25 May, 2012, University of Žilina.

[10] PYRHONEN, J.-JUSSILA, H.-ALEXANDROVA, Y.-RA FAJDUS, P.-NERG, J.: Harmonic loss calculation in rotor surface permanent magnets, An analytical approach, early access article, IEEE Trans. On Magnetics, ISSN: 0018-9464.

[11] PYRHNENJ.-RUUSKANEN, V.-NERG, J.-PURANEN, J.-JUSSILA, H. : Permanent Magnet Length Effects in ACMachines, IEEE Transactions on Magnetics 46 No. 10 (2010), 3783-3789, ISSN 0018-9464 (IF 1.061).

Received 29 September 2011

Peter Sekerák was born in Stará Lubovňa, Slovakia, in 1985. He received the MSc in 2009 in power electrical systems. He is now PhD student at the Department of Power Electrical Systems, University of Žilina. His research is focused on permanent magnet synchronous machines.

Valeria Hrabovcová graduated in electrical engineering from the University of Žilina and gained her PhD in electrical engineering from Slovak University of Technology in Bratislava in 1985. She is a full professor of electrical machines at University of Žilina, Faculty of Electrical Engineering, Slovakia. Her professional and research interests include classical, permanent magnets and electronically commutated electrical machines.

Juha Pyrhönen received the MSc degree in electrical engineering, the Licentiate of Science (Technology) degree, and the DSc degree (Technology) from Lappeenranta University of Technology (LUT), Lappeenranta, Finland, in 1982, 1989, and 1991, respectively. He has served as associate professor at Electric Engineering LUT, starting in 1993 and was appointed full professor in Electrical Machines and Drives in 1997. He worked as the head of the Department of Electrical Engineering from 1998 to 2006. He is active in the research on and development of electric motors and electric drives.

Lukáš Kalamen was born in 1986 in Myjava, Slovakia. After graduating at the Faculty of Electrical Engineering, University of ilina in 2009, he received the MSc degree in electrical drives. Currently, he is a $\mathrm{PhD}$ student at the same university. His main research interest includes electrical machines mainly wind power systems equipped with induction generators.

Pavol Rafajdus was born in Trnava, Slovakia, in 1971. He received the MSc degree in electrical engineering and the PhD from University of Žilina, Slovakia, in 1995 and 2002, respectively. At present he is an associate professor at the Faculty of Electrical Engineering, University of Žilina. His research is focused on the electrical machines, mainly switched reluctance motors and other electrical machine properties.

Matúš Onufer was born in Vranov n. T., Slovakia in 1987. He graduated from the University of Žilina, where he received the MSc in 2011 in power electrical engineering. He is now $\mathrm{PhD}$ student at the Department of Power Electrical Systems on the University of Žilina and his research is focused on synchronous machines with hybrid excitation. 